\title{
Hansen's disease: a vanishing disease?
}

\author{
Sinésio Talhari', Maria Aparecida de Faria Grossi ${ }^{2}$, Maria Leide WDR de Oliveira ${ }^{3}$, \\ Bernardo Gontijo ${ }^{4}$, Carolina Talhari ${ }^{1 /+}$, Gerson Oliveira Penna ${ }^{5}$
}

\begin{abstract}
1'Departamento de Dermatologia, Universidade Nilton Lins, Manaus, AM, Brasil ${ }^{2}$ Secretaria de Estado da Saúde, Fundação Hospitalar do Estado de Minas Gerais, Belo Horizonte, MG, Brasil ${ }^{3}$ Serviço de Dermatologia, Universidade Federal do Rio de Janeiro, Rio de Janeiro, RJ, Brasil ${ }^{4}$ Departamento de Dermatologia, Universidade Federal de Minas Gerais, Belo Horizonte, MG, Brasil ${ }^{5}$ Núcleo de Medicina Tropical, Universidade de Brasília, Brasília, DF, Brasil
\end{abstract}

The introduction, implementation, successes and failures of multidrug therapy (MDT) in all Hansen's disease endemic countries are discussed in this paper. The high efficacy of leprosy treatment with MDT and the global reduction of prevalence led the World Health Organization, in 1991, to establish the goal of elimination of Hansen's disease (less than 1 patient per 10,000 inhabitants) to be accomplished by the year 2000. Brazil, Nepal and East Timor are among the few countries that didn't reach the elimination goal by the year 2000 or even 2005. The implications of these aspects are highlighted in this paper. Current data from endemic and previously endemic countries that carry a regular leprosy control programme show that the important fall in prevalence was not followed by the reduction of the incidence. This means that transmission of Mycobacterium leprae is still an issue. It is reasonable to conclude that we are still far from the most important goal of Hansen's disease control: the interruption of transmission and reduction of incidence. It is necessary to emphasize to health managers the need of keeping Hansen's disease control activities to better develop control programmes in the future. The recent international proposal to interrupt the transmission of leprosy by the year 2020 seems to unrealistic and it is discussed in this paper. The possibility of epidemiological impact related to the human immunodeficiency virus/Hansen's disease coinfection is also considered.

Key words: leprosy - Mycobacterium leprae - therapy

Global situation of Hansen's disease after multidrug therapy (MDT) - In 1982, the WHO Study Group on the Chemotherapy of Hansen's Disease for Control Programme (WHO 1982) recognized an urgent need of new therapeutic approaches to face the problem of dapsone resistance detected in more than 40 endemic countries (WHO 1982, 1985). This study group strongly recommended the introduction of a new therapeutic regimen with association of drugs (dapsone, rifampicin and clofazimine) known as MDT. Multibacillary (MB) patients should be treated with all three drugs until the skin smears became negative and paucibacillary $(\mathrm{PB})$ patients would receive dapsone and rifampicin for six months.

MDT was implemented in all endemic countries through the 80 's and has always been available free of charge. WHO and non-governmental organizations (NGOs) played a major role in this process.

MDT promoted a shift in deep-seated paradigms among patients, health workers and population, such as leprosy being an incurable disease. Moreover, it was feasible in the field, showed efficacy rates greater than $99 \%$ in MB and PB patients, with few side effects and turned drug resistance into a minor problem (WHO 1991).

+ Corresponding author: carolinatalhari@gmail.com

Received 29 March 2012

Accepted 11 September 2012
Leprosy treatment, formerly a lifetime therapy in most Hansen's disease control programmes, was then possible to be discontinued. Later on, MDT duration for MB patients was successively reduced to two and one year and since 1982 MDT for PB patients has been administered for six months.

At the completion of MDT, programme managers were instructed to release patients from regular control and remove them from the official records. This policy resulted in a tremendous reduction in the global prevalence from more than five million registered patients in the 80's to less than one million at the end of the 90's (WHO 1985, 1991).

Success of MDT implementation and WHO goal of Hansen's disease elimination by the year 2000 - Following the success of MDT, but without strong or incontestable evidence, leprosy elimination was the next step proposed by the WHO and Health Ministries of endemic countries during the 44th World Health Assembly held in May 1991 (WHO 1991). This goal was defined as the reduction in prevalence to less than one patient per 10,000 inhabitants by the year 2000. It was assumed that such prevalence figures would so drastically impact the transmission of Mycobacterium leprae that, with time, leprosy would virtually be extinct and any resurgence unlike (WHO 1991).

The implementation of Hansen's disease elimination through MDT in all endemic countries, reaching patients even in very remote areas, is a hallmark in the leprosy control history (WHO 2003). WHO, NGOs and governments did a remarkable job together. Since 1985, more than 15 million patients have been cured through MDT (WHO 2010b). 
Impact of MDT in Hansen's disease prevalence and incidence: current status with special reference to Índia, Brazil and Indonesia - The global number of new cases of leprosy has steadily declined from the peak of more than 775,000 in 2001 to 245,000 in 2009 (WHO 2010a).

In 2004, India launched the Hansen's disease elimination monitoring with new standards for case definition in this country. These changes triggered a sudden drop of $63.6 \%$ in new reported cases from 367,143 in 2003 to 133,717 in 2009 . During the same time frame, global detection of new cases went down from 514,718 in 2003 to 244,796 in 2009 (WHO 2010a). In short, India is the leading responsible country for the world prevalence of leprosy (Figs 1,2).

Comparing the new leprosy cases detection trend among the three endemic countries - India, Indonesia and Brazil - it is observed that the last two countries presented a similar behaviour: a slow reduction of the incidence from 2002-2008. This trend is more compatible with the epidemiological behaviour of Hansen's disease, due to its long incubation period.

In Brazil, another major endemic country, Hansen's disease prevalence steadfastly declined and detection rates showed an increasing tendency in the last two decades of the 20th century, probably reflecting better patient access to primary health care (Penna et al. 2008).

From 2007-2010, important changes were introduced in Brazil regarding Hansen's disease public health policy. Disease control in patients less than 15 years of age and surveillance of contacts were defined as the most important strategies to reach the planned objectives. Epidemiological studies were able to spot clusters of cases and greater risk of disease, therefore providing scientific basis for political and administrative actions (Penna et al. 2008, 2011). During this period, the Brazilian Ministry of Health never hesitated in employing all governmental and diplomatic means available to include Hansen's disease control - in Brazil and around the world - into the framework of evidence-based medicine.

Hansen's disease control is based on early diagnosis and treatment, which allows the prompt elimination of transmission sources and the decrease of the hidden prevalence of infectious cases. However, the impact of Hansen's disease control strategies can not be compared to that of other vaccine preventable infectious diseases. The reason is that in high risk areas, a significant proportion of the adult population is already infected and may

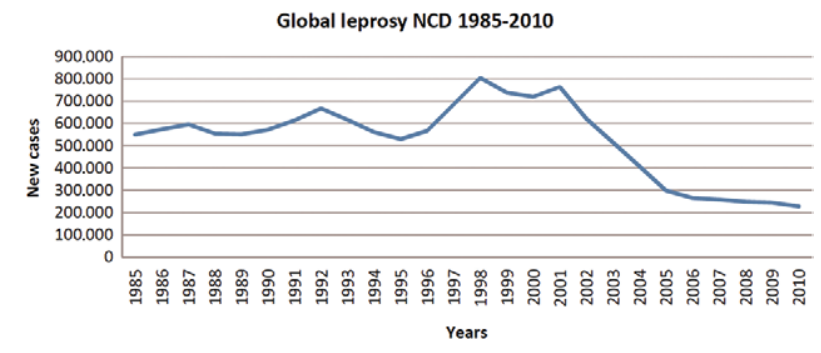

Fig. 1: global leprosy new case detection (NCD) between 1985-2010. Source: WHO (2012). develop the condition (Penna 1988). In order to reduce the hidden prevalence, one must foster case detection which, in turn, implies in the increase of the known prevalence.

In 2007, 10 clusters with a strong concentration of new cases were identified in Brazil. These areas, which comprised 173 of the nearly 5,000 Brazilian municipalities and $10 \%$ of the country population, accounted for $53.5 \%$ of the new cases reported (Penna et al. 2008, 2009). These areas were given top priority as to epidemiological surveillance, treatment, prevention of incapacities and rehabilitation (Penna et al. 2009, 2011).

The majority of endemic countries that reached the elimination goal did so by following World Health Organization guidelines (WHO 2003). However, statistical data from WHO must be interpreted with caution. According to Fine (2006), India's criteria for prevalence and detection are doubtful and questionable and, hence, it is quite likely that this country and maybe the whole world, has not reached yet prevalence rates established by the WHO for the elimination goal. Actions proposed by the India programme (Leprosy Elimination Monitoring) included recommendations that new cases could only be reported after diagnostic confirmation by a leprologist, patients with single lesion or relapsed patients should be excluded from prevalence and withdrawal of dropout patients from active records (Britton \& Lockwood 2004, Samy 2007).

Another intriguing aspect of Hansen's disease epidemiology is that, in spite of the efficacy of MDT and its wide use for over 25 years, the impact on the transmission of M. leprae is not as strong as expected (Britton \& Lockwood 2004, Rothman et al. 2008, Rodrigues \& Lockwood 2011). Although prevalence has dropped during the last two decades, incidence has fallen quite slowly (Penna et al. 2011). Also, prevalence decrease after the introduction of MDT was not paralleled by the decrease of new cases, indicating that prevalence is not a suitable parameter to measure disease control (Britton \& Lockwood 2004). According to the WHO, new cases of leprosy, although not many, are still diagnosed in countries that have reached the elimination goal, stressing the need for permanent actions from governments (Penna et al. 2011).

The number of countries with reported new cases has risen from 121 in 2008 to 141 in 2009. In 2008, six countries - China, Madagascar, Nepal, Nigeria, Sudan and Tanzania - showed an increase in new cases as compared to 2007. In 2009, Ethiopia, Philippines and Sudan detected more cases than in 2008 (WHO 2009, 2010a).

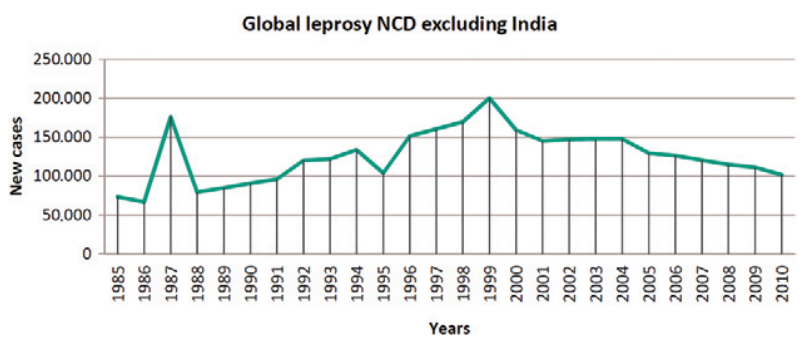

Fig. 2: global leprosy new case detection (NCD) trend excluding the data of India. Source: WHO (2012). 
Hansen's disease elimination and human immunodeficiency virus (HIV)/leprosy coinfection - Brazil is one of the countries where Hansen's disease and acquired immune deficiency syndrome (AIDS) are endemic. From 1980-2007, 506,499 cases of HIV infection were reported, with a detection rate of 17.8 cases per 100,000 inhabitants (MS/SVS 2008, WHO 2009, 2010a).

Worldwide data indicate that, contrary to early expectations, no significant increase in Hansen's disease and HIV coinfection has been reported (Ustianowski et al. 2006). Most of the large studies on the subject were performed in the early to mid-1990s, examining the rate of HIV seropositivity among leprosy patients in India (Sekar et al. 1994), Brazil (Andrade et al. 1997, Machado et al. 1998) and African countries (Poennighaus et al. 1991, Lienhardt et al. 1996). In Brazil, studies suggest that, in coinfected patients, each disease progresses as a separate infection (Sampaio et al. 1995, Pereira et al. 2004).

However, one study probably addressed the true estimate of the prevalence of leprosy and HIV infection in populations exposed to both diseases, in a cohort recruited in Manaus, a city located in the Brazilian Amazon Region, where both leprosy and AIDS are endemic. Considering that the institution where the study was conducted (Institute of Tropical Medicine) is a referral centre for both diseases, it is possible that the 25 cases of leprosy and HIV coinfection out of a total of 3,290 HIV-positive individuals reported between 1996-June 2009 (SINAN 2009) represent the closest estimate of the prevalence of this coinfection in a major Brazilian city. Since the prevalence of leprosy in the state of Amazonas was 2.92/10,000 in 2008, these data clearly indicates a higher Hansen's disease prevalence among HIV-positive individuals when compared to the general population (Talhari 2010).

Further studies are needed to better evaluate HIV/ leprosy coinfection and its impact on elimination goals. The emphasis on the reduction of grade 2 of physical deformity among new cases, as recommended by the last WHO Expert Panel, is a challenge for Hansen's disease control programmes and obligate that detection should be prioritized (Bobin 2005, WHO 2010b).

MDT, introduced in 1982, has been proved efficacious in Hansen's disease treatment. Withdrawal of treated patients from active records, resulting in a striking decrease of prevalence, stimulated WHO to propose, in 1991, the elimination of Hansen's disease by the year 2000. The top nine most endemic countries (India, Brazil, Nepal, Madagascar, Mozambique, Democratic Republic of Congo, Tanzania, Angola and Central African Republic) were not able to meet this deadline. The elimination goal was then postponed to 2005 .

By the year 2008, Brazil, Nepal and East Timor had failed to "eliminate" leprosy as a public health problem (Penna et al. 2011). The National Brazilian Program shifted the elimination goal to decrease of leprosy in child in the country-plan for 2008-2011, however, after the governmental changes, the current policy returned to the elimination goal.

Current epidemiological data from some countries must be carefully interpreted since the elimination targets by the year 2000 and even 2005 were obtained by cleaning of registers, changes in the case definition of Hansen's disease, single dose treatment for PB patients and reduction of treatment duration to one year, among others (WHO 1991, Bobin 2005, Talhari \& Penna 2005, Rodrigues \& Lockwood 2011).

\section{REFERENCES}

Andrade VL, Moreira AT, Avelleira JC 1997. Prevalence of HIV-1 in leprosy patients in Rio de Janeiro, Brazil. Acta Leprol 10: 159-163.

Bobin P 2005. Peut-on programmer l'éradication, l'élimination ou le contrôle d'une maladie infectieuse? L'exemple de la lèpre. Bull de l'ALLF 16: 3-8.

Britton WJ, Lockwood DNJ 2004. Leprosy. Lancet 363: 1209-1219.

Fine PE 2006. Global leprosy statistics: a cause for pride, or frustration? Lepr Rev 77: 295-297.

Lienhardt C, Kamate B, Jamet P 1996. Effect of HIV infection on leprosy: a three-year survey in Bamako, Mali. Int J Lepr Other Mycobact Dis 64: 383-391.

Machado P, David Y, Pedroso C, Brites C, Barral A, Barral-Netto M 1998. Leprosy and HIV infection in Bahia, Brazil. Int J Lepr Other Mycobact Dis 66: 227-229.

MS/SVS - Ministério da Saúde/Secretaria de Vigilância em Saúde 2008. Programa Nacional de DST-AIDS. Available from: aids. gov.br/data/Pages/LUMIS9A49113DPTBRIE.htm.

Penna MLF 1988. Uma abordagem ecológica da tuberculose. Cad Saude Publica 4: 356-362.

Penna MLF, Oliveira MLWR, Carmo EH, Penna GO, Temporão JG 2008. Influência do aumento do acesso à atenção básica no comportamento da taxa de detecção de hanseníase de 1980 a 2006. Rev Soc Bras Med Trop 41 (Suppl. 2): S1-S5.

Penna MLF, Oliveira MLWR, Penna GO 2009. The epidemiological behavior of leprosy in Brazil. Lep Rev 80: 332-344.

Penna MLF, Temporão JG, Grossi MAF, Penna GO 2011. Leprosy control: knowledge shall not be neglected. J Epidemiol Coтmunity Health 65: 473-474.

Pereira GA, Stefani MM, Araujo Filho JA, Souza LC, Stefani GP, Martelli CM 2004. Human immunodeficiency virus type 1 (HIV-1) and Mycobacterium leprae co-infection: HIV-1 subtypes and clinical, immunologic and histopathologic profiles in a Brazilian cohort. Am J Trop Med Hyg 71: 679-684.

Poennighaus JM, Mwanjasi LJ, Fine PE 1991. Is HIV infection a risk factor for leprosy? Int J Lepr Other Mycobact Dis 59: 221-228.

Rodrigues LC, Lockwood DNJ 2011. Leprosy now: epidemiology, progress, challenges and research gaps. Lancet Infect Dis 11: $464-470$

Rothman KJ, Greenland S, Lash TL 2008. Modern epidemiology, Lippincott Williams \& Wilkins, Philadelphia, 500 pp.

Sampaio EP, Caneshi JR, Nery JA 1995. Cellular immune response to Mycobacterium leprae infection in human immunodeficiency virus-infected individuals. Infect Immun 63: 1848-1854.

Samy AA 2007. Leprosy elimination - need for sample survey. Lepr Rev 78: 167-169.

Sekar B, Jayasheela M, Chattopadhya D 1994. Prevalence of HIV infection and high-risk characteristics among leprosy patients of south India - a case-control study. Int J Lepr Other Mycobact Dis 62: 527-531.

SINAN - Sistema de Informação de Agravos de Notificacação 2009. Casos de AIDS e taxa de incidência (por 100 mil habitantes) notificados ao SINAM em indivíduos maiores de 13 anos, segundo município de residência e anos de diagnóstico, no período 
de 2005 a 2009, e total acumulado de 1986 a 2009 na cidade de Manaus, Amazonas. Available from: aids.gov.br/cgi/deftohtm. exe?tabnet/am.def.

Talhari C 2010. Leprosy and HIV coinfection: a clinical, pathological, immunological, and therapeutic study of a cohort from a Brazilian referral center for infectious diseases. J Infect Dis 202: 345-354.

Talhari S, Penna GO 2005. Independent evaluation of GAEL (Global Alliance for Leprosy Elimination). Lepr Rev 76: 180-181.

Ustianowski AP, Lawn SD, Lockwood DNJ 2006. Interactions between HIV infection and leprosy: a paradox. Lancet Infect Dis 6: $350-360$

WHO - World Health Organization 1982. Chemotherapy of leprosy for control programmes. WHO Tech Rep Ser 675: 1-33.

WHO - World Health Organization 1985. Epidemiology of leprosy in relation to control. Report of a WHO Study Group. Tech Rep Ser 716: 1-60.
WHO - World Health Organization 1991. World Health Assembly 1991. Elimination of leprosy as a public health problem by the year 2000. Available from: who.int/lep/strategy/wha/en/index.html.

WHO - World Health Organization 2003. The final push strategy to eliminate leprosy as a public health problem. Questions and answers, 2nd ed., WHO, Geneva, 33 pp.

WHO - World Health Organization 2009. Global leprosy situation 2009. Wkly Epidemiol Rec 84: 333-340.

WHO - World Health Organization 2010a. Global leprosy situation 2010. Wkly Epidemiol Rec 85: 337-348.

WHO - World Health Organization 2010b. Leprosy (Hansen disease). Report by the Secretariat. Available from: apps.who.int/gb/ ebwha/pdf_files/EB128/B128_16-en.pdf.

WHO - World Health Organization 2012. Leprosy mailing list. Available from: http://leprosymailinglist.blogspot.com.br/2012/04/ who-news-release-final-push-needed-to.html. 